\title{
Escravidão e ordem política: uma comparação entre a Política de Aristóteles e $\boldsymbol{A}$ Utopia de Thomas More
}

\author{
Felipe Landim Ribeiro Mendes*
}

\begin{abstract}
Resumo: Este artigo pretende demonstrar como a escravidão aparece como ponto fundamental nas ordenações políticas de Aristóteles e Thomas More. Por meio de uma análise da Política e da Utopia, busca-se esclarecer como os dois filósofos enxergam o cativeiro como algo além do que uma simples relação de dominação ou modelo de trabalho, encontrando na instituição uma das balizas de suas sociedades ideais. Ao longo do artigo, far-se-á uma breve exposição sobre a natureza da escravidão, seguida da análise das obras de Aristóteles e More. Nas considerações finais, pretende-se encontrar os pontos de intersecção entre os escritos dos dois autores, bem como os elementos que afastam ambas as teorias.
\end{abstract}

Palavras-chave: Escravidão, Política, Aristóteles, Thomas More.

\section{Introdução}

A Lei Áurea brasileira de 1888 marcou o fim definitivo da escravidão nas Américas e colaborou com a instituição do padrão de trabalho livre e assalariado vigente durante o século XX. Desde então, a escravidão passou a ser vista como um desvio de regra, um ponto fora da curva ou, até mesmo, uma exceção na História. Essa impressão, contudo, logo se dissipa quando nos debruçamos sobre os modelos de trabalho de sociedades antigas e encontramos o cativeiro como padrão. Indo além, ratificamos essa percepção ao vermos que teorizações políticas de autores clássicos tem como ponto integrante o trabalho escravo (DrEscher, 2011; PATTERSon, 1982).

Aristóteles e Thomas More são dois desses autores que incluíram essa questão em suas obras de cunho político. 0 primeiro, ao escrever a Política, separa cinco capítulos do Livro I para tratar da natureza da escravidão e suas implicações para a ordem desejada. More, por sua vez, dedica o capítulo intitulado "Dos escravos", do Livro Segundo da obra A Utopia, à questão da redução de seres humanos à condição de escravos e de sua função na ilha idealizada. Mesmo que distantes no tempo, Aristóteles e More se aproximam nessa temática. Para ambos, a escravidão não era vista como uma instituição estranha à sociedade e que devesse ser abolida. Pelo contrário, da sua existência dependia o bom funcionamento da cidade que, nas visões de um e outro, se dava de maneiras distintas.

No desenvolvimento deste artigo, pretendo encontrar as especificidades do pensamento de cada um dos dois autores no que se refere ao trabalho escravo e confrontá-las. Aristóteles pensa a escravidão como natural e necessária à perfeita existência da polis, mas rejeita a coerção e a guerra como meios de suprimir a liberdade de um cidadão e torná-lo escravo. Thomas More também vê função social

* Graduando em História - USP 
na escravidão, mas não como um instrumento primordial de produção material e necessário à separação do trabalho braçal do intelectual. A instituição escravidão seria, na Utopia, um sorvedouro de marginalizados e substituta da morte como pena, tendo esta ideia de More ligação direta com a Inglaterra de seu tempo ${ }^{1}$.

Para atingir tais intentos, o artigo foi desmembrado em quatro partes. $\mathrm{Na}$ primeira delas, faço uma breve discussão sobre a natureza da escravidão e sua inserção na mentalidade das sociedades anteriores ao século XVI. Nas duas partes seguintes, que efetivamente constituem o núcleo do artigo, pretendo, na primeira delas, expor e analisar as teorizações sobre a escravidão feitas por Aristóteles no Livro I da Política, procurando as justificativas e restrições para a prática e, sobretudo, as implicações que a instituição traz para a ordem política, segundo o autor grego. Usando o mesmo método, procuro, num segundo momento, investigar a escravidão concebida por Thomas More nos capítulos da Utopia e seu papel político na ilha imaginada. Por fim, concluo o artigo confrontando os trabalhos dos dois autores, sintetizando as ideias comuns e destacando as especificidades das obras.

\section{"Uma instituição perene"2}

No livro Escravidão e morte social, o sociólogo Orlando Patterson define a escravidão como "dominação permanente e violenta de pessoas desenraizadas e geralmente desonradas" (PATTERSON, 1982, p. 34). Ainda que possa ser criticada devido à sua rigidez, a teoria do autor estadunidense encaixa-se em diversas sociedades escravistas que cobriram o globo desde tempos remotos até o século XX. Focada na interação senhor-escravo, sua definição baseia-se nas relações de poder existentes entre os dois elementos desse elo.

Se Patterson esmiuçou o jogo de poder imbricado entre os principais atores do jogo da escravidão - o senhor e o escravo -, Seymour Drescherprocura, na escala macro das relações de poder, a força dessa instituição que perdurou por tantos séculos. No prefácio de Abolição, Drescher divaga sobre a perenidade e aceitação de um regime de trabalho imbuído de implicações para a hierarquia social.

Por milhares de anos antes da metade do século XV, houve várias formas de escravidão em todo o mundo, e ela vicejou em regiões econômica e culturalmente desenvolvidas. A instituição foi considerada indispensável para o funcionamento contínuo das mais elevadas formas políticas e religiosas de existência e impôs limites ao modo como a ordem social poderia ser imaginada (DRESCHER, 2011, p. xiii).

A escravidão seria, segundo Drescher, o lugar comum. A mentalidade pretérita ao século XVI não permitia que se pensassem as formas sociais e políticas sem tomar o cativeiro humano como objeto. Drescher é categórico:

\footnotetext{
${ }^{1}$ Sobre A Utopia e o diálogo direto de More com o momento político e social inglês do século XVI, ver SANToS, 2009.

${ }^{2}$ Título do capítulo 2 do livro Abolição, de Seymour Drescher. Ver Drescher, 2011.
} 
Além da organização da sociedade, a escravização foi frequentemente concebida como modelo para a estrutura hierárquica do universo físico e da ordem divina. Dessa perspectiva, em um cosmos convenientemente ordenado, a instituição foi, em última análise, benéfica tanto para os escravizados quanto para seus senhores. Quaisquer que fossem os escrúpulos morais ou as racionalizações que pudessem estar ligados a qualquer uma de suas dimensões, a escravidão parecia fazer parte da ordem natural. Ela estava tão profundamente embutida nas relações humanas quanto a guerra e a miséria (Idem, ibidem, p. xiii-xiv).

Ainda que a naturalidade da escravidão fosse presente tanto na Grécia Clássica quanto na Inglaterra de inícios do século XVI, o modo como cada povo a enxergou foi distinto. Os "limites impostos pela escravidão à ordem social imaginada" - nos dizeres de Drescher - podem ser contemplados na Utopia de More e na Política de Aristóteles. É por esta última que iniciamos nossa análise.

\section{Política: A escravidão em Aristóteles}

Se procurássemos obras de meados e fins do século XVIII e início do XIX preocupadas com a escravidão das plantations americanas e o tratamento dado aos escravos, encontraríamos tratados sobre a administração das fazendas e de sua mão de obra (cativos), discussões filosóficas e morais sobre o porquê da escravidão negra e o alijamento de pessoas de cor dos direitos individuais, além de ferrenha discussão política, sobretudo na Europa e nos EUA, acerca do tráfico transatlântico de escravos e do futuro da produção escravista nas Américas (DRESCHER, 2011; MARQUESE, 2003).

Mergulhada na economia-mundo do século XIX, a política em torno da instituição escravista não podia ser descolada das aspirações financeiras. Ou seja, ainda que o âmbito político se constituísse num campo autônomo, suas correlações com outro campo também dotado de autonomia - o econômico - impedia que a escravidão fosse vista como objeto genuinamente político. ${ }^{3}$ A título de exemplo, a defesa da escravidão feita por fazendeiros cubanos nas Cortes espanholas era embasada em argumentos políticos - melhor forma de governo, tranquilidade na ilha, bem-estar de livres e escravos etc. - mas conectava-se primordialmente com a necessidade da mão de obra para a manutenção das altas taxas de lucro advindas da exportação de açúcar (BERBEL; MARQUESE; PARRON, 2010).

Por não ser perceptível no pensamento grego da época de Aristóteles a esfera econômica (do modo como a pensamos hoje), as teorizações do filósofo não esbarram nesse campo autônomo de forma direta. 0 filósofo Giuseppe Tosi define claramente a circunscrição do pensamento aristotélico sobre a escravidão.

\footnotetext{
${ }^{3}$ Sobre a impossibilidade de imputar à sociedade grega clássica plena consciência de uma esfera econômica autônoma, ver Rossi, M. A.; Tierno, P., 2009. Destacamos o trecho do artigo que traz a ideia de maneira concisa: “1) Quando falamos de economia devemos evitar todo tipo de anacronismo. É sabido que a antiguidade não teve ideia da economia como ciência autônoma; para isso foi necessário esperar o advento da modernidade” (p. 181).
} 
Aparece de forma clara, já desde a primeira página da Política, que a questão que mais interessa a Aristóteles é a multiplicidade dos tipos de governo (arché) e a sua justificação. É, portanto, nesse contexto, que deve ser lida a discussão sobre a escravidão; a questão central de Aristóteles é entender e justificar a existência de âmbitos e formas distintas de governo do homem sobre outro homem. Aristóteles quer definir e justificar a escravidão, mas também distinguir e preservar o espaço da liberdade dos cidadãos, os quais não podiam ser governados como se fossem escravos (Tosı, 2003, p. 73).

Aristóteles inicia o Livro I da Política explicando a origem da polis e as partes que a compõem. Os homens buscam o bem e, sendo a cidade a organização que agrupa todos os cidadãos, é nela que se dá a busca do bem maior. A polis, no entanto, não é uma escolha de organização social feita pelos moradores ou uma convenção entre os cidadãos. Para o filósofo grego, a polis ételos, i.e., o fim natural que deve ser alcançado pela interação entre os homens.

A primeira sociabilidade entre os componentes da polis se dá na união natural entre macho e fêmea, que formam, assim, o núcleo da casa. Desta primeira constatação, Aristóteles deriva outra tese que se relaciona estreitamente com a questão da escravidão grega: "Em primeiro lugar, aqueles que não podem existir sem o outro devem formar um par. É o caso da fêmea e do macho para procriar [...]; é ainda o caso daquele que, por natureza, manda e daquele que obedece, para segurança de ambos" (ARISTótELES, 1998, 1252a).

Aristóteles toma como verdade que, na organização política, há os designados a mandar e outros a obedecer e, como isto é um ordenamento natural, não há conflito entre governantes e governados. "É que quem pode usar o intelecto para prever, é, por natureza, governante e senhor, enquanto quem tem força física para trabalhar, é governado e escravo por natureza. Assim, senhor e escravo convergem nos interesses" (Ibidem, 1252a).

No último trecho citado, Aristóteles começa a desenhar sua analogia da dominação. Nela, o filósofo compara o organismo humano ao organismo social e decreta que, no primeiro, dividido em corpo e alma, esta deve mandar naquele; no segundo, o senhor aparece como o dominante e o escravo como o dominado. "Sem essa relação não seria possível a unidade do todo, que é o que permite a existência das partes: essa é a justificação da naturalidade das relações de domínio entre os homens" (Tosı, 2003, p. 80).

Aristóteles começa a desenvolver sua teoria da escravatura quando pretende discutir a administração da casa, da aldeia e, por fim, da polis. Como deseja chegar à melhor forma de governo da comunidade de cidadãos, o filósofo procura, primeiramente, entender como se dá a economia doméstica, apresentando-nos três relações que julga primordiais: senhor e escravo; marido e mulher; pai e filhos. (Ibidem, 1252a). Aristóteles, no entanto, se detém mais longamente na primeira relação e passa a investigar a escravidão em si.

A propriedade é uma parte da família, e a arte de adquirir bens uma parte da administração da casa, já que sem os bens de primeira necessidade não só não se pode viver como não se pode viver bem. E tal como na administração da casa, à semelhança 
do que sucede em artes específicas, é necessário dispor de instrumentos próprios para a tarefa que tem de ser desempenhada, [...] (Ibidem, 1253b, grifos meus).

0 trecho acima nos mostra, ainda que implicitamente, o que Aristóteles vê como a função predominante dos escravos na melhor ordenação possível da polis. As tarefas que devem ser desempenhadas pelos cidadãos só podem ser levadas a cabo por meio de instrumentos específicos para isso. Para que o indivíduo livre possa ser efetivamente um cidadão e participar ativamente das deliberações e decisões da comunidade, é necessário que as atividades estranhas a essa sua atuação sejam desempenhadas por instrumentos que lhe pertençam. 0 escravo, num primeiro momento, não passa de uma propriedade animada de seu senhor: "[...] o escravo é uma espécie de propriedade viva e todo o ajudante é como que o primeiro de todos os instrumentos" (Ibidem, 1253b).

Aristóteles prossegue com sua conceituação do escravo e, ao mesmo tempo, deixa mais claro qual o papel que lhe cabe na boa ordenação social e busca pelo bem comum.

Estas considerações tornam evidente o que são a natureza e a faculdade de ser escravo: aquele que, por natureza, sendo humano, não pertence a si próprio, mas a outrem, é escravo por natureza. Um ser humano pertence a outro se, apesar de humano, for objeto de propriedade; e uma propriedade é um instrumento destinado à ação e com existência autônoma (Ibidem, 1254a).

O escravo é escravo por natureza, não por coerção ou redução futura. Sua função é como propriedade animada de um senhor e, só assim, contribui para o melhor funcionamento da sociedade. Chegamos a um dos pontos-chave de nossa questão. A importância da escravidão no pensamento aristotélico está na sua função de produção material ${ }^{4}$. 0 escravo, tomado como propriedade, participa da boa saúde da polis ao permitir que os livres por natureza possam exercer sua cidadania sem as amarras do trabalho braçal. 0 escravo é um apêndice do senhor, uma parte deste destinada a exercer as atividades que um homem livre, a fim de melhor participar das decisões políticas da cidade, não pode realizar.

Temos aqui uma constatação interessante. Na cidade ideal aristotélica, os cidadãos se dedicam à contemplação, ao ócio, ao logos, às artes, à ginástica, à guerra, à poesia, à deliberação. São esses homens, desgarrados das amarras do trabalho braçal e da produção material, que formam o corpus dos cidadãos e que tornam a polis uma perfeita organização social. É evidente, no entanto, que outro grupo seja imbuído das obrigações das quais os cidadãos são dispensados. É aí que o escravo entra como instrumento de ação, não apenas de produção. Sua função não se confunde com a dos artesãos e trabalhadores livres. 0 escravo é a parte do senhor

\footnotetext{
${ }^{4}$ Quando dizemos que a função do escravo é a produção material, não queremos que se confunda o escravo com um simples instrumento de produção (órganonpoietikón). Na dinâmica interna da polis, o trabalho do escravo não é um fim em si, mas um exercício que permite que seu senhor chegue à plena realização humana. Assim, o escravo deve ser visto como um instrumento de ação (órganonpraktikón), na medida em que é parte animada do senhor e permite que este exerça atividades da práxis (Tosı, 2003, p. 78).
} 
que cumpre os deveres da economia doméstica, já que este está impossibilitado de fazê-lo. É o escravo que, afastado da cidadania, permite que ela exista.

Aristóteles procura pontuar as vantagens de um escravo designado naturalmente para sê-lo em oposição à escravidão antinatural. Segundo o estagirita, o escravo por natureza é o que pode prover uma relação não conflituosa com o seu senhor. "É óbvio, então, que uns são livres e outros escravos, por natureza, e que para estes a escravidão é não só adequada mas também justa" (Ibidem, 1255a). Sucede que essa adequação e justeza da escravidão não se encaixam quando um homem é tornado escravo em detrimento de sua natureza. Aristóteles utiliza o exemplo dos escravos de guerra para demonstrar as injustiças que seriam cometidas em casos assim e como homens virtuosos, que melhor contribuiriam para a sociedade se instalados entre os magistrados, fossem colocados na posição de escravos.

Existem ainda outros que tendendo, segundo pensam, para uma certa forma de justiça (já que a lei é uma forma de justiça) consideram que a escravatura na guerra é sempre, e em qualquer parte, justa. Mas contradizem-se porque a causa das guerras pode não ser justa e ninguém pode reconhecer como escravo, de maneira alguma, a quem não o merece ser (Ibidem, 1255a, grifos meus).

O trecho grifado mostra a aversão de Aristóteles à possibilidade de um indivíduo que não foi naturalmente designado à condição de escravo ser colocado em tal posição por meio da guerra. Pior que isso é se o reduzido à escravidão pela guerra fosse de "nobre nascimento" e fosse impedido de exercer atividades intelectuais mais profundas. "Por outro lado, pode suceder que os considerados de mais nobre nascimento se tornem escravos e descendentes de escravos, caso sejam capturados e vendidos" (Ibidem, 1255a).

É possível perceber que a perfeita escravidão para o filósofo se dá sem conflito, sem coerção ou uso da força. Partindo do pressuposto que o senhor é designado a mandar e o escravo a obedecer, ambos por natureza, anula-se a possibilidade de atrito entre os dois membros. Assim, o complexo senhor-escravo formaria uma espécie de corpo único, coeso e dinâmico, em que a função de cada membro seria pré-determinada e haveria harmonia. Importante frisar que isso só ocorre em senhores e escravos designados naturalmente para sê-los.

Mas um exercício errado do poder é contrário aos interesses de ambos [senhor e escravo]; é que a mesma coisa beneficia tanto a parte como o todo, a alma como o corpo, e o escravo é como que uma parte de seu senhor, uma espécie de parte animada do corpo deste, mas uma parte separada. Por esta razão, existe uma convergência de interesse e amizade recíprocas entre o senhor e o escravo que merecem o respectivo estatuto por natureza. Mas quando não é este o caso, e senhor e escravo o são por convenção e violência, sucede o contrário (Ibidem, 1255b).

Partindo do quadro traçado em cima da teoria aristotélica da escravidão, 
focaremos agora a função social desempenhada pelos escravos no livro A Utopia, de Thomas More, bem como as justificações que este dá para a instituição.

\section{A Utopia: A escravidão em Thomas More}

A Utopia pode ser considerada a maior contribuição que a Renascença do Norte deu à teoria política (SANTOS, 2009, p. 65). Essa informação parece irrelevante para o tratamento do tema a que nos propomos aqui, mas é necessária para pontuarmos uma questão que perpassa não só a teoria da escravatura em Thomas More, mas também a de Aristóteles. A Utopia, assim como a Política, são textos de teóricos que se preocupam primordialmente com o ordenamento da comunidade, com a ordem política. Evidentemente, na medida em que traçam as características ideais que suas sociedades deveriam conter, ambos invadem outras esferas do plano social para aperfeiçoar o modelo desejado. 0 fim, no entanto, é sempre político.

Se a escravidão é parte integrante tanto da obra de Aristóteles quanto da de More, fica patente sua importância na ordem que ambos desejam para a comunidade. 0 cativeiro não é considerado como simples modalidade de trabalho, mas sim uma instituição que compõe o âmago da organização entre os homens. É exatamente por isso que tratamos até aqui - e continuaremos a tratar adiante - a escravidão como instrumento político.

Diferentemente de Aristóteles, More não se debruça exaustivamente sobre a natureza da escravidão, a fim de explicar suas origens imemoriais. Assim, para chegarmos a um entendimento de qual é a função que Thomas More delega a esta instituição, devemos compreender o projeto construído pelo autor na Utopia e, a partir dele, encontrar o real lugar da escravidão e sua função nessa sociedade ideal.

Após as reflexões e discussões sobre a situação da Inglaterra e referências a lugares distantes feitas no Livro Primeiro, More faz no Livro Segundo, pela boca de Rafael Hitlodeu, uma descrição de todas as características sui generis de uma ilha: a Utopia. Rafael nos conta da geografia do local, da organização de suas cidades, dos magistrados, das artes e ofícios, das viagens dos cidadãos e o que mais nos interessa - dos escravos. Como dito, não será possível determo-nos apenas nesse capítulo para compreendermos a natureza de seu conteúdo. Ainda assim, devido às dimensões do artigo, pretendemos não extrapolar em demasia os limites desse tópico e concentrar a discussão em torno do que More/Hitlodeu nos diz.

\footnotetext{
Nem todos os prisioneiros de guerra são indistintamente entregues à escravidão, mas unicamente os indivíduos capturados de armas na mão.

Os filhos de escravos não são escravos. 0 escravo estrangeiro torna-se livre ao tocar na terra da Utopia.

A servidão recai particularmente sobre os cidadãos culpáveis de grandes crimes e sobre os condenados à morte pertencentes ao estrangeiro. Estes são muito numerosos na Utopia; os utopianos vão mesmo procurá-los no exterior onde os compram a vil preço; algumas vezes obtêm-nos até de graça (More, 2010, p. 75).
}

Podemos retirar algumas informações importantes do trecho acima. Existem diversas restrições à redução de um indivíduo à escravidão na ilha Utopia. Numa 
incursão bélica não são todos os prisioneiros que podem ser escravizados, os filhos de escravos não são também cativos e escravos de outra região que chegam à ilha tornam-se automaticamente livres. Apreende-se, observando apenas este trecho, três modos de produção de escravos:

\begin{abstract}
primeiro, criminosos utopianos que recebem a forma mais severa de penalidade, pois sua educação e criação são motivos suficientes para evitar o erro; segundo, prisioneiros de guerra, já que os utopianos consideram criminosas as pessoas que lutam contra eles, por isso fazem cumprir pena na ilha; e, terceiro, os condenados à morte noutros lugares e comprados pelos utopianos estão cumprindo penas judiciais (Collins, 2010, p. 72).
\end{abstract}

Um ponto que nos chama atenção é a impossibilidade de uma ligação direta entre a produção material e o trabalho escravo. 0 que ficava, de certa maneira, nítido em Aristóteles, em que a base da produção deveria ser suprida com trabalho de escravos por natureza, é menos claro nas teorizações sociais e políticas de Thomas More. Não há uma separação tão peremptória entre o trabalho do cidadão e o trabalho do escravo, ratificado pela estrutura social da ilha e pela obrigatoriedade de trabalho a todos. Alguns trechos ajudam a esclarecer essa questão.

Assim, todos, na Utopia, vivem ocupados em artes e ofícios realmente úteis. 0 trabalho material é de curta duração e mesmo assim produz a abundância e o supérfluo. Quando há acúmulo de produtos, os trabalhos diários são suspensos e a população é transportada em massa para reparar estradas esburacadas e estragadas. Na falta de obras comuns ou extraordinárias a realizar, um decreto autoriza uma diminuição nas horas de trabalho, porque o governo não procura fatigar seus cidadãos em labores inúteis (More, 2010, p. 50).

Fica evidente, no trecho, como não há necessidade material extrema do trabalho escravo, já que os cidadãos são realocados para obras coletivas em caso de superabundância e têm inclusive sua jornada de trabalho diminuída em casos de falta de obras comuns. More/Hitlodeu não cita a presença de escravos em situações como essas, o que nos faz crer que ou eles estão incluídos nessa lógica ou não participam dessas atividades. Se excluímos a função unicamente produtiva do escravo de More/ Hitlodeu, devemos investigar qual seria a necessidade de o autor teorizar um Estado que contém escravos.

Há ainda outra espécie de escravos, os trabalhadores pobres das regiões vizinhas que vêm se oferecer voluntariamente para trabalhar. São em tudo tratados como cidadãos; apenas são obrigados a trabalhar um pouco mais, uma vez que têm o hábito de fadiga maior. São livres para partir quando querem e nunca são devolvidos de mãos vazias (Ibidem, p. 75).

More apresenta-nos neste parágrafo outro modo de se conseguir escravos na Utopia. Devemos observar, porém, que não se tratam efetivamente de escravos, já que o autor nos diz que "são em tudo tratados como cidadãos". Ora, aqui devemos estabelecer uma relação com os condenados à morte comprados como escravos. 
Neste último caso, temos indivíduos degradados (afinal foram condenados por terem cometido algum crime grave), desvirtuados que seriam mortos em sua terra de origem. Esse desvio de virtude nos parece ser o ponto fulcral da escravidão na Utopia. Os pobres de outras regiões chegam a ser tratados na ilha quase como cidadãos, já que não apresentam nenhum desvio de conduta. Mark Collins chega até mesmo a dizer que "a escravidão [na Utopia] é encarada primariamente como uma condição penal" (Collins, 2010, p. 73).

Essa conclusão foi possível pela análise da situação dos estrangeiros que chegam à ilha e oferecem-se como escravos. É possível confirmarmos essa visão se estendermos esse raciocínio aos meios de acesso a escravos moradores da própria Utopia. Comparemos os dois trechos que seguem:

Todos os escravos são submetidos a um trabalho contínuo, e trazem correntes. Os que são tratados, porém, com mais rigor, são os indígenas, que são tidos como os mais miseráveis dos celerados, dignos de servir de exemplo aos outros por uma pior degradação. Com efeito, eles receberam todos os germes da virtude; aprenderam a ser felizes e bons, e, no entanto, abraçaram o crime (MORE, 2010, p. 75).

Aquele que por sua própria vontade se permitir franquear os limites de sua província é tratado como criminoso; apanhado sem licença do príncipe, é reconduzido como desertor e severamente punido. Em caso de reincidência, perde sua liberdade (Ibidem, p. 59).

No primeiro trecho, a pior escravidão recai sobre os indígenas que, tendo contato com a virtude, deixam-se levar pelo crime. No segundo, vê-se como a escravidão funciona como uma punição, um sorvedouro de criminosos e marginalizados da sociedade. Parece-nos que a função social e política da escravidão na sociedade idealizada por Thomas More está aí. Evitando outros tipos de penas como prisão ou morte, os utopianos escravizam os criminosos para puni-los e, no melhor dos casos, regenerá-los. É, finalmente, a ferramenta da qual os utopianos se utilizam para controlar a população e manter a ordem.

A pena ordinária, mesmo para os maiores crimes, é a escravidão. [...] Mas os que suportam pacientemente a sua sorte não perdem de todo a esperança. Veem-se infelizes que, domados pelo tempo e pelo rigor dos sofrimentos, testemunham verdadeiro arrependimento, mostrando que o crime lhes pesa com mais força do que o castigo. Então, a prerrogativa do príncipe, ou a voz do povo, concede-lhes a liberdade (Ibidem, p. 78).

Não há atuação da natureza na escravatura da Utopia. Esta se dá como um meio de coerção social e ordenação da ordem política, na medida em que absorve um contingente de criminosos e desvirtuados, passando a empregá-los em atividades que podem, em certos casos, reinseri-los na comunidade. A escravidão não se explica pela necessidade de produção material, e sim pela manutenção da ordem, evitando a aplicação da pena capital.

É interessante observar que, mesmo baseado na escravidão, o sistema de controle utopiano é avançado em relação à realidade da Europa de More. Se serve 
como ímã que atrai os indesejados à ordem da ilha, o cativeiro funciona também como um "sistema penal [que] é reformativo, ao invés de punitivo, e é um grande avanço em relação à prática europeia" (Collins, 2010, p. 73). 0 diálogo com o contexto em que More escreveu a Utopia é direto. Advogando contra a pena de morte, o autor "testa" outro modelo de punição e regeneração de indivíduos na comunidade imaginada, a fim de contrapor-se ao praticado na Inglaterra.

\section{Considerações finais}

A escravidão é parte integrante e fundamental das sociedades descritas por Aristóteles e More, o que nos permite aproximar autores tão distintos. Ambos a consideram um elemento aglutinador da comunidade, preservador da ordem e legítimo - ainda que façam distinção quanto à natureza e ao uso da instituição.

No caso do filósofo grego, os escravos seriam requisitados para cumprir a função braçal de produção que um cidadão ateniense não poderia exercer. Já no caso do inglês, a escravidão é uma alternativa à pena de morte, uma válvula de escape para os marginalizados da sociedade e um meio de manter a ordem do Estado. More também crê na força para reduzir um indivíduo à condição de escravo, enquanto Aristóteles vê na escravidão natural, nos laços entre dominador e dominado a grande chave para uma relação virtuosa e sem conflitos.

Um ponto comum que deve ser salientado é a percepção que ambos tinham da relação escravista como algo benéfico tanto à parte dominante quanto à parte dominada. Se essa constatação fica patente em Aristóteles, já que este chega a dizer literalmente em sua obra que o cativeiro é benéfico tanto para o senhor quanto para o escravo, em More ela aparece de forma tácita. Se, no entanto, analisarmos o fim último da instituição na Utopia, vemos a assertiva de Drescher ${ }^{5}$ ser confirmada. O escravo, ainda que passando por privações, teria na sua condição de servo a possibilidade de reinserir-se socialmente e reformar-se moralmente, tornando a instituição, por fim, benéfica tanto para o escravo quanto para o senhor - que, no caso da sociedade coletivista utopiana, seria a própria comunidade de cidadãos.

Novamente, vemos como a escravidão é ponto crucial nas duas obras. A definição de cidadania - termo caro a Aristóteles e definidor da identidade do povo ateniense - só pode ser construída tomando-se o ente escravo como o agente que possibilita a ação do cidadão. Sem ele, não há polis ideal. 0 mesmo pode-se dizer da instituição na Utopia: a base do sistema penal da Ilha - baliza do Estado suis generis idealizado por More - é a escravidão, que aglutina os degenerados, os põe a serviço da comunidade e, no limite, os reintegra à sociedade. Sem a escravatura, tanto a obra de More quanto a de Aristóteles perderiam um dos entes definidores do Estado ideal que ambas buscam erigir. Se o tempo distancia um filósofo do outro, a escravidão os aproxima.

\footnotetext{
${ }^{5}$ Referimo-nos, aqui, à passagem já citada: "Além da organização da sociedade, a escravização foi frequentemente concebida como modelo para a estrutura hierárquica do universo físico e da ordem divina. Dessa perspectiva, em um cosmos convenientemente ordenado, a instituição foi, em última análise, benéfica tanto para os escravizados quanto para seus senhores [...]" (DRESCHER, 2011).
} 
É importante reafirmar também o papel que o cativeiro desempenha na Política e na Utopia. Tomando o termo "Política" como arte ou ciência do Governo, ou mesmo como esfera de ações deliberadas que têm por fim a melhor organização da sociedade, Aristóteles e More pensam a escravidão dentro desse ramo. Os dois autores veem o trabalho compulsório de indivíduos como um meio para se atingir a melhor sociedade.

Primordiais para o entendimento de sociedades escravistas, as obras de Aristóteles e More podem ser interessantes meios de compreensão das funções que o trabalho, tanto compulsório quanto livre, cumpre nas sociedades de hoje.

\section{Referências Bibliográficas}

Aristóteles. (1998). Política. Tradução de António Campelo Amaral e Carlos Gomes. Lisboa, Veja.

Berbel, M. ; Marquese, R.; Parron, T. (2010). Escravidão e política: Brasil e Cuba, c. 1790-1850. São Paulo, Hucitec.

Brugnera, N. L. (1998). A escravidão em Aristóteles. Porto Alegre, Editora Grifos.

Collins, M. I. (2010). A filosofia moral e política na Utopiade Thomas Morus. 86f. Dissertação (Mestrado em Filosofia) - Departamento de Filosofia, Universidade Federal do Ceará, Fortaleza.

DRESCHER, S. (2011). Abolição: uma história da escravidão e do antiescravismo. Tradução de Antonio Penalves Rocha. São Paulo, Editora Unesp.

MARquese, R. de B. (2004). Feitores do corpo, missionários da mente: senhores, letrados e o controle dos escravos nas Américas, 1660-1860. São Paulo, Companhia das Letras.

MoRE, T. (2010). A Utopia. Tradução de Luís de Andrade. São Paulo, Edipro.

Patterson, O. (2008). Escravidão e Morte Social: Um Estudo Comparativo. Tradução de Fábio Duarte Joly. São Paulo, Editora da Universidade de São Paulo.

Rossi, M. A.; Tierno, P. (2009). "A dimensão econômica da teoria política aristotélica". Lua Nova, São Paulo, n. 77, p. 179-204.

SANTos, A. S. dos. (2009). "A Utopia de Thomas More: o debate político e a imersão no seu tempo". Humanidades em diálogo, São Paulo, vol. III, n. I, p. 57-71.

TosI, G. (2003). "Aristóteles e a escravidão natural". Boletim do CPA, Campinas, n. 15, jan./jun., p. 71-100.

Recebido em janeiro/2014

Aprovado em março/2014 